\title{
Understanding the Gap Between Desire for and Use of Consumer Health Solutions
}

\author{
- \\ INVITED ESSAY \\ Jennifer Zelmer, PHD, MA \\ Executive Vice-President \\ Canada Health Infoway \\ Simon Hagens, BSc, MBA \\ Director, Benefits Realization \\ Canada Health Infoway \\ $\infty$
}

\begin{abstract}
Modern healthcare is more complex than ever before, with a broader range of care providers, organizations, diagnostic approaches and treatments. The result is that accurate and timely information is more important than ever. In response, clinical use of health information technology has grown significantly in recent years and there is growing interest in the use of consumer health solutions. In this article, the authors discuss the current landscape of the latter in Canada, enablers and barriers to their adoption and our readiness for change.
\end{abstract}


From ancient times, information has been central to health and healthcare. Huntergatherer societies needed to know which plants would relieve pain and which would make them sick. Healers have long sought to identify symptoms and how best to alleviate them. But modern healthcare is more complex than ever before, with a broader range of care providers, organizations, diagnostic approaches and treatments. The result is that accurate and timely information is more important than ever and there is more of it to manage.

In response to these trends, clinical use of health information technology has grown significantly in recent years. What were once novel developments, such as digital imaging for radiographs and computed tomography (CT) scans or online indexing services that make it easy to search the global health literature, are now commonplace. The adoption of electronic medical records in primary care, while uneven and still lower than in some other countries, is also rising steadily in Canada. Rates now top 70\% in some parts of the country (Health Council of Canada 2013). Similar growth in use has been seen for other point-of-care solutions, as well as for shared repositories of core clinical data, such as patient and provider demographics, laboratory test results and prescription medication profiles (Canada Health Infoway 2013a).

The use of digital health by individuals is, in contrast, at a much earlier stage. Innovators have been trialling consumer health solutions for a number of years, from simple applications (apps) that track physical activity to sophisticated approaches that provide an integrated set of services connecting individuals with healthcare providers and supporting them in managing their health. While there are strong pockets of use, these types of functions are still relatively new in Canada and elsewhere. For example, Ipsos Reid surveys in
2010 and 2013 suggest that there is a substantial gap between the more than eight in 10 Canadians who say that they would like to have access to their own health information online and the $4 \%$ who report they do. Similar situations exist for several other types of consumer health solutions.

\section{There is a substantial gap between the more than eight in 10 Canadians who say that they would like to have access to their own bealth information online and the $4 \%$ who report they do.}

This paper outlines current interest in and use of digital health by individuals, with a focus on the most popular types of solutions. Given the gap between the desire for and availability of such services, it also explores a number of questions that have been asked about their implementation, in the hope of sparking further discussion and debate.

\section{High Interest in Using Consumer Health Solutions}

Banking, booking hotels and flights, making restaurant reservations and connecting with friends and family - these are just a few examples of the growing use of online services in many aspects of our daily lives. Most major consumer-facing industries are involved, and widespread use of smartphones and tablets is only accelerating the trend.

Healthcare is no different. An interest in taking advantage of technology to improve the patient experience is high. For example, consultations with more than 500 individual Canadians, healthcare providers, governments, administrators, associations and vendors about how digital health could best support their 
future health and healthcare needs identified opportunities for action between now and 2018 (Canada Health Infoway 2013b). Among the top five priorities were bringing care closer to home (e.g., with mobile patient monitoring, online access to personal health information and related solutions) and providing easier access to care through e-visits, e-scheduling and similar services.

Surveys have confirmed Canadians' interest in these areas (Table 1). For instance, more than eight in 10 adults say that they would like to have online access to their own health information, such as laboratory test results (Ipsos Reid 2010). Among other services that surveys suggest would be well used are appointment booking, requesting prescription renewals and secure messaging or e-visits.
- Make interacting with multiple healthcare providers better and easier (77\%)

- Make accessing healthcare services easier and more convenient (76\%)

- Help keep them informed about their health and/or the health of those for whom they are caregivers (76\%)

- Make the healthcare system more efficient (74\%)

- Allow them to take more control over their health and how it is managed (69\%)

- Lead to better health outcomes for themselves (64\%)

- Result in more quality time between them and their healthcare providers at appointments (59\%)

Table 1. Adult Canadians' preferences regarding consumer digital health solutions

\begin{tabular}{|c|c|c|}
\hline Solution & $\%$ Desiring Solution & $\begin{array}{l}\% \text { Selecting as } \\
\text { Single Most Valued }\end{array}$ \\
\hline Request prescription renewal & 90 & 26 \\
\hline View laboratory test results & 88 & 20 \\
\hline Make appointments with healthcare providers & 87 & 15 \\
\hline $\begin{array}{l}\text { Consult with providers securely online without having to } \\
\text { phone or visit their office }\end{array}$ & 79 & 10 \\
\hline All other solutions tested & $74-90$ & $\leq 5 \%$ each \\
\hline
\end{tabular}

Source: Data from an Ipsos Reid survey (2010).

Nine in 10 adults say that they would be moderately or extremely comfortable with using such electronic consumer health solutions if they were available to them (Ipsos Reid 2013). Comfort levels tend to be higher among those who live in a metropolitan area, are in the middle-income category (\$40K-\$80K household income) and are under the age of 35 years (Ipsos Reid 2013). Respondents to a 2013 survey agreed that these types of solutions would (Ipsos Reid 2013) accomplish the following:
In contrast, the approximately $10 \%$ of respondents who said that they were uncomfortable with using consumer health solutions most often cited the risk of the system being compromised or safety/security concerns (Ipsos Reid 2013). Among informal caregivers and those who use the health system most often who said that they were not comfortable with such tools, the leading reason named was a preference to see physicians in person. 
The Current Landscape: Use of Consumer Health Solutions

Use of consumer health solutions is on the rise internationally. For example, the Commonwealth Fund surveyed primary care physicians in seven countries about email use in 2006 and 2012 (Commonwealth Fund 2013). Between 3\% (Canada) and $17 \%$ (New Zealand) of respondents said that they sometimes or often communicated with their patients by email regarding treatment in 2006. Six years later, more than twice as many practices in all countries surveyed said that their practice allowed patients to email about a medical question (from 11\% in Canada to $45 \%$ and $46 \%$ in Germany and the Netherlands, respectively). Trends are not available, but Switzerland's rate in 2012 was even higher, with more than two thirds of primary care physicians (68\%) emailing patients (Table 2).
The experience of early adopters suggests that uptake can be strong where digital health services that patients value are offered. For example, by 2010, Kaiser Permanente in northern California had signed up 64\% of members for online access, and its 7,000 physicians had received 5.8 million secure messages (Baer 2011). More recent data show four million Kaiser members registered to use secure features, and more than 88 million sign-ons in 2012 alone (Kaiser Permanente 2013). Lower uptake in some other contexts reinforces the importance of strong usercentric design and features, as well as alignment with patient and provider expectations and workflows (Robert Wood Johnson Foundation 2012).

While rising, the use of consumer health solutions in Canada is still in relatively early stages (see Table 2). For example, patients who have tests at participating laboratories in

Table 2. Primary care physicians who reported that their practice allows patients to perform three services online in 2012

\begin{tabular}{|c|c|c|c|}
\hline Country & $\begin{array}{l}\text { Request Appointments } \\
\text { or Referrals (\%) }\end{array}$ & $\begin{array}{l}\text { Request Refills for } \\
\text { Prescriptions (\%) }\end{array}$ & $\begin{array}{l}\text { Email about a Medical } \\
\text { Question }(\%)\end{array}$ \\
\hline Australia & 8 & 7 & 20 \\
\hline Canada & 7 & 6 & 11 \\
\hline France & 17 & 15 & 39 \\
\hline Germany & 22 & 26 & 45 \\
\hline Netherlands & 13 & 63 & 46 \\
\hline New Zealand & 13 & 25 & 38 \\
\hline Norway & 51 & 53 & 26 \\
\hline Sweden & 66 & 88 & 41 \\
\hline Switzerland & 30 & 48 & 68 \\
\hline United Kingdom & 40 & 56 & 35 \\
\hline United States & 30 & 36 & 34 \\
\hline
\end{tabular}

Source: Data from Commonwealth Fund (2013). 
British Columbia are invited to register for online access to their results as soon as these results are released by the laboratory. Access is either via a secure website or smartphone application, with results available in English, French, Punjabi and Chinese (Excelleris Technologies 2013). As of August 2013, Excelleris reported more than 360,000 users (Excelleris 2013, August 7). Similarly, Sunnybrook Hospital's MyChart personal health record has been used by over 15,000 patients, family members and clinicians since it became active in 2006 (Chung et al. 2012). The hospital continues to expand functionality and use over time, including personal and family health information, appointment requests, questionnaires, test results, symptom and medication diaries, e-messaging with participating clinicians and staff and other functions.

\section{Recent data show four million Kaiser members registered to use secure features, and more than 88 million sign-ons in 2012 alone.}

Recent surveys (Ipsos Reid 2010, 2013) suggest that less than $10 \%$ of adults have consulted with a healthcare provider, booked an appointment, requested a prescription renewal or viewed health record information, such as laboratory test results, online. Usage appears to be higher among those who use the health system most often. However, for all groups it is well below the number of people who say that they would like to be able to use these types of services (Ipsos Reid 2013).

\section{Looking Ahead: Enablers and Barriers}

The gap between interest in and use of consumer health solutions has at least as much - perhaps more - to do with the context in which such solutions might be implemented as with the technologies themselves. Early adopters have shown that navigating the cultural, regulatory, policy and legislative landscapes is key to the adoption and effective use of consumer health solutions. Important enablers to digital health success in general that were identified in recent consultations governance and leadership; policy and legislation; financing; resource capacity, capability and culture; practice and process changes; privacy and security; interoperability of solutions; and business case and benefits realization - definitely apply to this domain (Canada Health Infoway 2013b). There are also additional considerations that are more specific to consumer health solutions.

This section explores a number of the questions that may be asked when considering whether, how and how quickly to implement consumer health solutions, as well as emerging evidence and experience that is beginning to clarify many of the issues involved.

\section{What Is the Effect on Health or Healthcare Quality?}

As with any new technology, it is important to understand how the use of consumer health solutions might affect access to health services, quality of care and efficiency/productivity, as well as the overall patient experience. Some contend that there is tremendous potential for improving health with greater access to care, better communication with healthcare providers and innovative use of technologies to support patient-centred care and self-management of chronic disease. Others worry about safety risks, patients' abilities to interpret health records and whether virtual services can substitute for in-person care.

Evidence of the effects of consumer health solutions on health and healthcare quality is currently limited but growing. Many of 
the published studies come from the United States. For instance, Kaiser Permanente has studied the effects of e-visits and other consumer health solutions in its patient population (Zhou et al. 2010). The authors found improvements in effectiveness of care for diabetes and hypertension, as well as 2-6.5 percentage point performance improvements on measures such as glycemic level (glycosylated hemoglobin, or HbA1c), cholesterol level and blood pressure screening and control.

A systematic review that included literature between January 1999 and December 3, 2010, asked about the relationship between secure messaging and various outcome measures (Goldzweig et al. 2012). It found moderate-strength evidence for improvements in patient satisfaction and glucose outcomes for patients with diabetes, as well as lowstrength evidence for supporting adherence to recommended care or outcomes for a number of other conditions. The review also asked about the effects associated with patient access to their own health records. It found lowstrength evidence of improvements in health outcomes for certain chronic diseases and changes in utilization, as well as insufficient evidence to determine whether there was an impact on efficiency.

A rapid response report prepared by the Canadian Agency for Drugs and Technologies in Health (CADTH) covering a similar time frame (January 1, 2005-October 18, 2010) added grey literature to the search parameters (CADTH 2010). The authors came to similar conclusions, stating, "Evidence suggests that patient use of personal electronic health records may have a positive impact on relationships between healthcare providers and patients and on some health outcomes; however more research is necessary in order to make conclusions regarding clinical and costeffectiveness" (CADTH 2010: 1). A number of recent studies have endeavoured to address some of the gaps in the literature highlighted in these and similar reviews:

- Health professionals using secure messaging with patients at the US Department of Veterans Affairs (VA) report improved access and patient perceptions about access, more direct and effective communication (e.g., because it was asynchronous) and changing communication patterns including enhanced relationships (Nazi 2013).

- Participants indicated that the workload had been manageable so far, but some did express concerns about implications as use grows. A separate VA study found associations between secure messaging use and reductions in urgent care use, particularly for early adopters (Shimada et al. 2013).

- A comparison of e-visits and in-person visits for sinusitis and urinary tract infections found similar rates of return follow-up visits, higher rates of antibiotic prescribing, lower rates of test ordering and lower overall costs for e-visits (Mehrotra et al. 2013a).

- A study of over 7,000 patient-generated secure messages and e-visits from the Mayo Clinic found that about 3.5\% of communications discussed potentially high-risk symptoms. No deaths within 30 days were related to the exchanges. While 47 emergency department visits and hospitalizations within seven days were related to issues discussed in the secure messages or e-visits, the authors reported that message responses "did not appear to have major safety concerns" (North et al. 2013: 1146-47).

- A more recent systematic review of the effects of use of personal health records identified five studies with original research (Kalra and Fernando 2013). Effectiveness benefits were found in three 
cases, patient-centredness benefits in one and results in both areas in another study. None reported harmful effects.

- Another study from the VA suggests potential benefits to patients having access to health professionals' notes regarding their care. It reported positive reactions from patients, including an increased sense of empowerment (Woods et al. 2013). Likewise, a quasi-experimental multi-site study in primary care (the "open notes trial") found that $87 \%$ of patients involved accessed at least one note (Delbanco et al. 2012). Many reported feeling more in control of their care (77-87\%) and increased medication adherence (60-78\%), whereas about a third (26-36\%) had privacy concerns and 1-8\% said that they experienced confusion, worry or offence from reading the notes.

- The use of consumer health solutions has been associated with improved adherence with therapy for human immunodeficiency virus (HIV) (Keith McInnes et al. 2013). In the case of diabetes, recent studies have shown that consumer health solutions use is associated with more frequent blood glucose monitoring by adolescents (Cafazzo et al. 2012) and improved glycemic control, plus better patient satisfaction and perceived access to care (Wade-Vuturo et al. 2013). Likewise, a Kaiser Permanente study showed that patients with diabetes who used an online patient portal for medication refills were more likely to adhere to statins therapy and had better dyslipidemia results than those who did not (Sarkar et al. 2014).

\section{Is It Fair? Equity Considerations}

Equitable access to care is one of the core principles underlying Canada's health system, and publicly funded healthcare has a redistributive effect. If patients were paying out of pocket, healthcare costs would be about $3 \%$ of the average income for the most affluent citizens and 24\% for the least affluent (Canadian Institute for Health Information 2013). Given that access to technology and health literacy may be correlated with income, questions have been raised about the effect of consumer health solutions on equitable access to care. On the other hand, some see these types of tools as improving equity since they may reduce the need to take time off work or pay travel costs to receive care.

Reports in the literature are mixed. While some studies have identified potential barriers to the adoption of consumer health solutions among low-income populations (Goldzweig et al. 2012), others have described applications that are effective at meeting the needs of this group. For example, text4baby is a mobile phone app that sends text messages to pregnant women and new mothers with information on their health, their baby's health and health resources available to them. Research has shown that it is both targeting and reaching minority groups and those with lower socio-economic status (Hoff et al. n.d.). Furthermore, in a study of four primary care practices in which almost $7 \%$ of consultations for sinusitis and urinary tract infections were e-visits, younger patients and those with longer travel distances were most likely to opt for a virtual visit but higher income was not associated with e-visit use (Mehrotra et al. 2013a). In Canada, surveys suggest that the availability and use of consumer health solutions are similar across income levels (Harris Decima 2012; Ipsos Reid 2013). Likewise, while self-reported comfort with consumer health solutions tends to be lower among older adults, actual usage is similar for those age 55 years plus and younger adults (Ipsos Reid 2013). In contrast, the same survey found that individuals who used more health services in general were more likely than the general population to use consumer 
health solutions.

Canadian and international experiences imply that there is the opportunity for the introduction of consumer health solutions to improve (or at least be neutral to) equity of access. While little is currently known about how different implementation approaches for these specific types of solutions affect access by potentially vulnerable groups, there is a rich literature on the implications of the "digital divide" across various sectors of the economy and society, as well as strategies to reduce its impact. Further investigation of the experiences of early adopters may also be informative. For example, a Kaiser Permanente study of patients with diabetes who were taking statins found that those with inadequate health literacy and those who were married were more likely to use a patient portal to refill their medications (Sarkar et al. 2014). There was no significant difference in participation rates by education level or for those with limited English proficiency.

\section{What Are the Effects on Workload and Productivity?}

Many healthcare providers considering implementing consumer health solutions have questions about the effects on workload and productivity. Some believe that the change will result in increased appointments and strained schedules; others feel that addressing straightforward needs online will be more efficient and free up highly skilled clinicians for complex cases or allow them to expand access to care.

Workload effects are easiest to assess for simpler solutions that have a single focus, such as e-scheduling applications. For example, these tools have been shown to reduce no-show rates through better patient access and the use of alerts and reminders. Other benefits cited include time savings and fewer interruptions to workflow, which allows

administrative staff to spend more time delivering high-quality patient services (Ludwick and Doucette 2009). As a result, the return on investment can be relatively rapid. For instance, one study reported that costs were recouped within six months in a primary care practice (Ludwick and Doucette 2010). It also indicated that practices with predictable, repetitive scheduling workflows benefitted most from online scheduling.

For more complex consumer health solutions, as with information systems in general, much appears to depend on the context in which such solutions are used, their design and their alignment with practice patterns and workflow. The experience of early adopters suggests that careful change management is required to optimize their use. For instance, Kaiser Permanente has one of the largest such implementations. Researchers have reported an association with improved quality outcomes (at least in primary care) and patient satisfaction, but mixed effects in terms of the use of other health services (Baer 2011; Palen et al. 2012). Likewise, a study from the VA looked at the effects of patients having access to health professionals' notes regarding their care. The authors reported unclear changes in overall clinic workload, but there were indications that changes to workflow and different types of engagement/communication between providers and patients were required to achieve full benefit (Woods et al. 2013).

There were indications that
changes to workflow and
different types of engagement/
communication between
providers and patients were
required to achieve benefit.

There were indications that

changes to workflow and

communication between

providers and patients were

required to achieve benefit. 
A recent US study interviewed leaders, clinicians and staff at a number of medical groups that use secure messaging in primary care (Bishop et al. 2013). Researchers found that it was "widely perceived to be a safe, effective, and efficient means of communication that improves patient satisfaction and saves patients time but that increases the volume of physician work unless office visits are reduced" (Bishop et al. 2013). They reported a number of strategies that the groups involved found to be effective in managing workload, such as having messages triaged by staff other than physicians or achieving cost savings under capitated payment models by shifting some office visits to e-visits.

The potential for patients to accrue significant time savings is reinforced by a recent Conference Board of Canada study. It drew on survey data and economic models to estimate that if Canadians had had the option to consult with their physicians, access test results and request prescriptions renewals electronically, they could have saved almost 70 million hours in 2011 (Conference Board of Canada 2012). This includes 18.8 million fewer hours off work and 51 million extra hours to spend on non-paid activities such as education, volunteer work and leisure. This analysis is based on potential time saved from a patient perspective.

\section{Questions about Patient Access to Health Information}

In 1992, the Supreme Court of Canada confirmed the right of patients to be able to access their personal health information, with very few exceptions (Canadian Medical Protective Association [CMPA] 2010). This right applies regardless of whether records are on paper or in an electronic format. Nevertheless, there are differing views regarding what types of information should be made available to patients online, in what time frame (e.g., whether there should be a delay on the release of test results) and whether the format or context should be the same or different from that available to clinicians.

In qualitative research conducted by Harris Decima in 2011, physicians were asked about their views on patients accessing their own personal health information. Most agreed that electronic records are patients' property and that what they can receive today on paper, they have a right to be able to see electronically (Harris Decima 2012). That said, a number of participants expressed reservations about patients having full access to their records, referencing the anxiety that this might cause and the difficulties in interpreting physicians' notes. Some also questioned whether there could be a section for physicians' working notes that would be "hidden" from the patient.

Current practice in Canada also varies. For example, some organizations that host consumer health solutions provide laboratory test results to patients and ordering clinicians at the same time, while others share results only after clinical review/release or a time delay.

This diversity of views was reflected in a recent Accenture survey of physicians in eight countries (Accenture 2013). Respondents were asked what type of access patients should have to their electronic health record. Canada's rates were close to the cross-national average: almost a third of Canadian physicians surveyed (29\%) said full access, 57\% recommended limited access and $14 \%$ said no access. Degrees of comfort varied depending on the type of information under discussion.

Other studies suggest that this variation may in part reflect the need to understand and work through associated issues. Examples include cost and security concerns, assignment of responsibility among the various individuals involved (e.g., whether test results will be made available immediately or only after clini- 
cal review) and tensions between patient and clinician expectations (Beard et al. 2012).

Interestingly, in Canada and other countries, support appears to increase as clinicians have more exposure to consumer health solutions. For example, Sunnybrook reports the following experience after implementing MyChart: "Concerns about patient access to information and the effect on the physicianpatient relationship have diminished to the point that clinician groups are now approaching Sunnybrook IS to reduce the number of delays. Clinicians are asking for more features and information for patients to be included in $\mathrm{MyChart}^{\mathrm{TM}}$ to help improve the patientphysician relationship as well as clinician office efficiency" (Chung et al. 2012: 13).

Similar results were seen in the "open notes trial," a multi-site quasi-experimental study in primary care (Delbanco et al. 2012). Authors reported that many physicians experienced trepidation before implementation; however, after the trial, 85-91\% said that enabling patients to access their records was "a good idea."

\section{How Ready Are We for Change?}

The use of consumer health solutions that enable patients to access their health records online at will, to book appointments or to request prescription renewals online reflects significant shifts from traditional models of care. Some argue that the transition should be easy or that it will happen naturally as a result of consumer demand; after all, the technology that underlies many consumer health solutions is well established. Email - even secure email - is used by millions, perhaps billions, around the world every day. So is online booking. Others point out the profound logistical, policy, legislative, cultural and other complexities involved, which may constitute barriers to adoption.

While many are supportive in principle, reactions to the implementation of consumer health solutions have been mixed. On the one hand, many of the early innovations have been driven by health professionals who have championed greater involvement of patients in their own care (Rich 2013). The Canadian Medical Association's General Council also recently endorsed the exploration of a complementary patient-controlled electronic health record (Canadian Medical Association 2013). On the other hand, many clinicians express concern about issues such as the completeness and accuracy of records, patients' reaction to information in their health records, privacy issues and effects on workload and workflow (Yau et al. 2011).

Many of the issues involved are not new, but they resurface as new modes of practice are discussed. Regulatory colleges, insurers, ministries of health, professional associations and others are beginning to grapple with some of the issues involved. For example, how to compensate clinicians for virtual services is being discussed in several jurisdictions. Substantial progress has been made in the context of telehealth, but discussions are generally at an earlier stage with regard to the provision of health services through secure messaging and other channels. Likewise, CMPA recently updated its guidance on the legal risks of using email to communicate with patients, citing "confidentiality, privacy, and security; timeliness of responses; and clarity of communication" as important considerations (CMPA 2013). Research points to the importance of clinician engagement and endorsement for the successful adoption and use of consumer health solutions. A study from the United States is one of the few to be conducted with health professionals from multiple disciplines (Nazi 2013). It found that key factors for clinicians in the implementation and adoption of consumer health solutions included perceived relevance; relative advantage versus traditional approaches; education and training; fit with 
workflow, structure, processes and existing technology; incentives; easy access to information from patients; and the way that different types of communication (e.g., asynchronous secure messaging) support collaboration. Likewise, a qualitative study in Southwestern Ontario among family physicians found three key facilitators for the adoption of personal health records: integration with existing systems; ease of use, with minimal impact on resources (time, money); and demonstrated added value to family practice (Yau et al. 2011).

\section{Conclusion and Recommendations}

While more than eight in 10 Canadians say that they would like to have access to their own health information online, only $4 \%$ report that they currently have such access. There are similar gaps for the ability to book appointments, request prescription renewals and consult with healthcare providers electronically. These types of services are relatively new around the world, and rates of use are rising. Levels of adoption in Canada today are lower than those of the global leaders - a gap that we have the potential to close by leveraging the country's digital health infrastructure and using consumer health solutions to support key health policy directions, such as a desire to improve access to care and the management of chronic conditions.

\section{Clearly, one size will not fit all.}

In many parts of the country, there is momentum to increase the use of consumer health solutions. Clearly, one size will not fit all. Implementation approaches need to take into account differences in patient populations, care environments, the broader digital health infrastructure and how to realize anticipated benefits. A user-centric design is key to success, as is alignment with patient and provider expectations and workflows.

Initiatives by early adopters show that, while technical advances are required, accelerating the use of consumer health solutions is not primarily a technology challenge. Emerging evidence is helping to frame the discussion and to separate myth from reality. Nevertheless, many important questions remain in areas such as ethics; healthcare culture; clinical workflow, regulation and compensation; legislation; and more. As experience evolves, both in Canada and globally, we need to focus on resolving remaining issues in order to reduce risk and to speed the successful use of consumer health solutions. This will help to shape implementation decisions and approaches to maximize long-term value for all Canadians.

\section{References}

Accenture. 2013. Doctors Survey: Canada Country Profile - Do Canadian Doctors Embrace Health IT? Chicago, IL: Author. Retrieved August 20, 2013. <http://www.accenture.com/SiteCollectionDocuments/ Local_Canada/PDF/Accenture-Doctors-SurveyCanada-Country-Profile.pdf $>$.

Baer, D. 2011. "Patient-Physician E-Mail Communication: The Kaiser Permanente Experience." Journal of Oncology Practice 7(4): 230-33.

Beard, L., R. Schein, D. Morra, K. Wilson and J. Keelan. 2012. "The Challenges in Making Electronic Health Records Accessible to Patients." Journal of the American Medical Informatics Association 19(1): 116-20.

Bishop, T.F., M.J. Press, J.L. Mendelsohn and L.P. Casalino. 2013. "Electronic Communication Improves Access, But Barriers to Its Widespread Adoption Remain." Health Affairs 32(8): 1361-67.

Cafazzo, J.A., M. Casselman, N. Hamming, D.K. Katzman and M.R. Palmer. 2012. "Design of an mHealth App for the Self-management of Adolescent Type 1 Diabetes: A Pilot Study." Journal of Medical Internet Research 14(3): e70. 
Canada Health Infoway. 2013a. Annual Report 2012-2013. Author: Montreal. Retrieved August 20, 2013. <https://www.infoway-inforoute.ca/index. $\mathrm{php} /$ resources/infoway-corporate/annual-reports/ doc_download/1876-annual-report-2012-2013>.

Canada Health Infoway. 2013b. Opportunities for Action: A Pan-Canadian Digital Health Strategic Plan. Author: Montreal. Retrieved August 29, 2013. <https://www.infoway-inforoute.ca/index. $\mathrm{php} /$ resources/infoway-corporate/vision/doc download/1843-opportunities-for-action-a-pancanadian-digital-health-strategic-plan>.

Canadian Agency for Drugs and Technologies in Health. 2010. Personal Electronic Health Records: Clinical Effectiveness, Cost-Effectiveness, and Clinical Practice Guidelines. Ottawa, ON: Author. Retrieved August 20, 2013. <http://www.cadth.ca/media/pdf/ K0267_Personal_Electronic_Health_Records_final. pdf $>$.

Canadian Institute for Health Information. 2013. Lifetime Distributional Effects of Publicly Financed Health Care in Canada. Ottawa, ON: Author.

Retrieved August 20, 2013. <https://secure.cihi.ca/ free_products/Lifetime_Distributional_Effects_AiB_ EN.pdf>.

Canadian Medical Association. 2013. Resolutions Adopted (Unconfirmed): 146th Annual Meeting of the Canadian Medical Association. Ottawa, ON: Author. Retrieved September 10, 2013. < from http://www. cma.ca/2013-resolutions-adopted-unconfirmed>.

Canadian Medical Protective Association. 2010. Medico-legal Handbook for Physicians in Canada (7th ed.). Ottawa, ON: Author. Retrieved August 20, 2013. <http://www.cmpa-acpm.ca/cmpapd04/docs/ resource_files/ml_guides/com_medico_handbook-e. cfm>.

Canadian Medical Protective Association. 2013. Using Email Communication with Your Patients: Legal Risks. Ottawa, ON: Author. Retrieved August 26, 2013. <http://www.cmpa-acpm.ca/cmpapd04/docs/ resource_files/infosheets/2005/com_is0586-e.cfm>.

Chung, K., S. Cheng, K. Rose, S. Marafioti and K.J. Leonard. 2012. "The Development and Change Management Strategy of Sunnybrook Health Sciences Centre's MyChart ${ }^{\mathrm{TM}}$." Electronic Healthcare 10(3): e10-14.

Commonwealth Fund. 2013. Surveys: International Health Policy. New York: Author. Retrieved August 20, 2013. <http://www.commonwealthfund.org/Surveys/ View-All.aspx?topic=International+Health+Policy> .

Conference Board of Canada. 2012. Valuing Time Saved: Assessing the Impact of Patient Time Saved from the Adoption of Consumer Health Solutions. Ottawa, ON: Author. Retrieved August 20, 2013. <https:// www.google.ca/url?sa $=$ t\& $\mathrm{rct}=\mathrm{j} \& \mathrm{q}=\& \mathrm{kesrc}=\mathrm{s} \& \mathrm{frm}=1$ \&source $=$ web\&cd $=2 \& v e d=0$ CDQQFjAB\&url=http s\%3A\%2F\%2Fwww.infoway-inforoute.ca\%2Findex. php $\% 2$ Fcomponent $\% 2$ Fdocman $\% 2$ Fdoc download\%2F628-valuing-time-saved\&ei=1qEoUvnNqinsQSnrYDQCg\&usg=AFQjCNEi9v6vg0iiDjO GDSej9i>.

Delbanco, T., J. Walker, S.K. Bell, J.D. Darer, J.G. Elmore, N. Farag et al. 2012. "Inviting Patients to Read Their Doctors' Notes: A Quasi-experimental Study and a Look Ahead." Annals of Internal Medicine 157(7): 461-70.

Excelleris. 2013, August 7. Big thanks to everyone for subscribing to my ehealth! We now have 360,558 subscribers! \#myehealth \#excelleris \#HealthCare [Tweet]. Retrieved August 26, 2013. <https://twitter. com/Excelleris/status/365214763006967808>.

Excelleris Technologies. 2013. myehealth. Burnaby, BC: Author. Retrieved August 29, 2013. <http://www. excelleris.com/our-solutions/myehealth/>.

Goldzweig, C., A. Towfigh, N. Paige, G. Orshansky, D. Haggstrom, J. Beroes et al. 2012. Systematic Review: Secure Messaging Between Providers and Patients, and Patients' Access to Their Own Medical Record: Evidence on Health Outcomes, Satisfaction, Efficiency and Attitudes. Washington, DC: Department of Veterans Affairs. Retrieved August 26, 2013. <http://www.ncbi.nlm.nih.gov/pubmed/22973584>.

Health Council of Canada. 2013. How Do Canadian Primary Care Physicians Rate the Health System? Results from the 2012 Commonwealth Fund International Health Policy Survey of Primary Care Physicians. Ottawa, ON: Author. Retrieved August 20, 2013. $<$ healthcouncilcanada.ca: http://healthcouncilcanada. ca/dl_check.php?id $=444 \& t p=1>$.

Hoff, A., A. Nunez-Alvarez, K.M. Martínez and D.Y. Lacoursiere. n.d. Maternal and Newborn Health: Text4baby San Diego Evaluation Overview: October 2011-October 2012. Retrieved August 26, 2013. $<$ http://www.csusm.edu/nlrc/documents/report archives/Text4Baby_SanDiego_Evaluation_Overview. pdf $>$.

Kaiser Permanente. 2013. Kaiser Permanente HealthConnect ${ }^{\circledR}$ Electronic Health Record: Frequently Asked Questions. Pasadena, CA: Author. Retrieved August 26, 2013. <http://xnet.kp.org/newscenter/ aboutkp/healthconnect/faqs.html>.

Kalra, D. and B. Fernando. 2013. "A Review of the Empirical Evidence of the Healthcare Benefits of Personal Health Records." Yearbook of Medical Informatics 8(1): 93-102. 
Keith McInnes, D., S. Shimada, S. Rao, A. Quill, M. Duggal, A. Gifford et al. 2013. "Personal Health Record Use and Its Association with Antiretroviral Adherence: Survey and Medical Record Data from 1871 US Veterans Infected with HIV." AIDS and Behavior 17(9): 3091-100.

Ludwick, D.A. and J. Doucette. 2009. "Improve Office Efficiency by Putting Your Patients to Work: Workflow Implications of an Online Self-Service Appointment Scheduling System in a Family Practice Office - Part 1 of 3." Electronic Healthcare 8(2): e14-18.

Ludwick, D.A. and J. Doucette. 2010. “Improve Office Efficiency by Putting Your Patients to Work: The Financial Viability of an Online Self-Service Appointment Scheduling System in Family Practice (Part 2 of 3)." Electronic Healthcare 8(3): e17-20.

Mehrotra, A., S. Paone, G.D. Martich, S.M. Albert and G.J. Shevchik. 2013a. "A Comparison of Care at E-visits and Physician Office Visits for Sinusitis and Urinary Tract Infection." JAMA Internal Medicine 173(1): 72-74.

Mehrotra, A., S. Paone, G.D. Martich, S.M. Albert and G.J. Shevchik. 2013b. "Characteristics of Patients Who Seek Care via eVisits Instead of Office Visits." Telemedicine Journal and e-Health 19(7): 515-19.

Nazi, K.M. 2013. “The Personal Health Record Paradox: Health Care Professionals' Perspectives and the Information Ecology of Personal Health Record Systems in Organizational and Clinical Settings." Journal of Medical Internet Research 15(4): e70.

North, F., S.J. Crane, R.G. Stroebel, S.S. Cha, E.S. Edell and S.M. Tulledge-Scheitel. 2013. "PatientGenerated Secure Messages and Evisits on a Patient Portal: Are Patients at Risk?" Journal of the American Medical Informatics Association 20(6): 1143-49.

Palen, T.E., C. Ross, J.D. Powers and S. Xu. 2012. "Association of Online Patient Access to Clinicians and Medical Records with Use of Clinical Services." Journal of the American Medical Association 308(19): 2012-19.
Rich, P. 2013. "Plugged-In Patients: New Tools Allow Doctors to Connect with Patients." Future Practice June: 8-11.

Robert Wood Johnson Foundation. 2012. Lessons Learned: The Value of Personal Health Records and Web Portals to Engage Consumers and Improve Quality. Princeton, NJ: Author. Retrieved July 30, 2013. <http://www.rwjf.org/content/dam/farm/reports/ issue_briefs/2012/rwjf400251>.

Sarkar, U., C.R. Lyles, M.M. Parker, J. Allen, R. Nguyen, H.H. Moffet et al. 2014. "Use of the Refill Function through an Online Patient Portal Is Associated with Improved Adherence to Statins in an Integrated Health System." Medical Care 52(5): 453.

Shimada, S., T. Hogan, S. Rao, J. Allison, A. Quill, H. Feng et al. 2013. "Patient-Provider Secure Messaging in VA: Variations in Adoption and Association with Urgent Care Utilization." Medical Care 51(3 Suppl. 1): S21-28.

Wade-Vuturo, A., L. Mayberry and C. Osborn. 2013. "Secure Messaging and Diabetes Management: Experiences and Perspectives of Patient Portal Users." Journal of the American Medical Informatics Association 20(3): 519-25.

Woods, S., E. Schwartz, A. Tuepker, N. Press, K. Nazi, C. Turvey et al. 2013. "Patient Experiences with Full Electronic Access to Health Records and Clinical Notes through the My HealtheVet Personal Health Record Pilot: Qualitative Study." Journal of Medical Internet Research 15(3): e65.

Yau, G.L., A.S. Williams and J.B. Brown. 2011. "Family Physicians' Perspectives on Personal Health Records: Qualitative Study." Canadian Family Physician 57(5): e178-84.

Zhou, Y.Y., M.H. Kanter, J.J. Wang and T. Garrido. 2010. "Improved Quality at Kaiser Permanente through E-Mail between Physicians and Patients." Health Affairs 29(7): 1370-75. 